DE

M E D I C I N A

T R O P I C A L

$\mathrm{DE}$

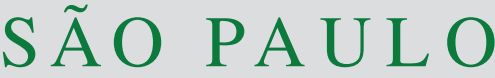

JOURNAL OF THE SÃO PAULO INSTITUTE OF TROPICAL MEDICINE

${ }^{1}$ Faculdade do Pantanal, Cáceres, Mato Grosso, Brazil

${ }^{2}$ Universidade do Estado de Mato Grosso, Faculdade de Ciências Agrárias e Biológicas, Programa de Pós-Graduação em Ciências Ambientais. Cáceres, Mato Grosso, Brazil

${ }^{3}$ Centro de Excelência do Instituto Joanna Briggs, Centro Brasileiro para o Cuidado à Saúde Informado por Evidências, São Paulo, São Paulo, Brazil

${ }^{4}$ Universidade Federal de Mato Grosso, Hospital Universitário Júlio Miller, Cuiabá, Mato Grosso, Brazil

Correspondence to: Omar Ariel Espinosa Faculdade do Pantanal, Av. São Luiz, 2522, CEP 78200-000, Cáceres, MT, Brazil Tel: +55 65 99999-5940

E-mail: omar.espinosa@fapan.edu.br

Received: 12 June 2020

Accepted: 12 June 2020

\section{Prevalence of comorbidities in patients and mortality cases affected by SARS-CoV2: a systematic review and meta-analysis}

\author{
Omar Ariel Espinosa ${ }^{\circledR 1}$, Andernice dos Santos Zanetti ${ }^{\circledR 2}$, Ednardo \\ Fornanciari Antunes ${ }^{(1)}$, Fabiana Gulin Longhi ${ }^{\circledR 3}$, Tatiane Amorim de \\ Matos $^{\circledR 2}$, Paula Franciene Battaglini ${ }^{\circledR 4}$
}

\section{ABSTRACT}

The new coronavirus, COVID-19 was declared a pandemic by the World Health Organization on March 11, 2020. Risk factors associated with this disease are age, sex, and the presence of comorbidities, the most common being hypertension, diabetes, and heart disease. The aim of this meta-analysis was to calculate the prevalence and geographical distribution of comorbidities in all patients admitted to intensive care units (ICUs), and the mortality rate of COVID-19. We selected studies based upon epidemiological and clinical descriptions of the patients and mortality from the disease to determine the pooled prevalence of comorbidities in all patients and in mortality cases due to COVID-19. The pooled prevalence was estimated using the random effects model, and odds ratios were used to measure the probability of death for a patient with a comorbidity. The total prevalence of comorbidities in patients with COVID-19 was $42 \%$ (95\% CI: 25-60), 61\% (95\% CI: 42-80) in those admitted to the ICU, and $77 \%$ (95\% CI: 68-86) among death cases; males were the most affected. Hypertension was the most prevalent comorbidity in all three groups studied, accounting for $32 \%, 26 \%$, and $35 \%$, respectively. The odds ratio of death for a patient with a comorbidity compared to one with no comorbidity was $2.4(P<0.0001)$. The higher the prevalence of comorbidities the higher the odds that the COVID-19 patient will need intensive care or will die, especially if the pre-existing disease is hypertension, heart disease, or diabetes.

KEYWORDS: COVID-19. SARS-CoV2. Prevalence. Comorbidity. Mortality. Meta-analysis.

\section{INTRODUCTION}

The 2019 pandemic coronavirus (COVID-19) has affected more than three million people in 211 countries, causing more than two hundred thousand deaths as of the end of April 20201. The etiologic agent of this disease is the severe acute respiratory syndrome coronavirus 2 (SARS-CoV2), which is transmitted through contact with infected persons or contaminated fluids ${ }^{2,3}$.

Several risk factors are associated with this disease. In a multicenter cohort study, advanced age was found to be significantly correlated with overall COVID-19 prevalence, which is consistent with the higher incidence observed in older adults ${ }^{4}$. The sex is another risk factor as a higher prevalence has been seen in men than women ${ }^{4}$. Other studies have shown that the presence of any comorbidity increases the chances of COVID-19 infection causing respiratory failure and death in patients ${ }^{5}$. Another study reports that patients admitted to the intensive care unit (ICU) had a higher number of comorbidities (72.2\%) than those not admitted to 
the ICU $(37.3 \%)^{6}$. Hence, comorbidities are considered a risk factor for fatality, and data from other reports show up to a $90 \%$ prevalence of comorbidities in fatal cases ${ }^{7}$, with cardiovascular diseases, diabetes, hypertension, chronic obstructive pulmonary disease being the most prevalent known comorbidities in COVID-19 cases $^{8}$.

Currently, several published studies describe the epidemiological and clinical characteristics of patients and mortality cases affected by COVID-19 in different parts of the world. For this reason, the aim of this meta-analysis was to estimate the prevalence and geographical distribution of comorbidities in all patients, in those admitted to the ICU, and in mortality cases affected by COVID-19 using the previously published data.

\section{METHODS}

The protocol for this systematic review was published in the International Prospective Registry of Systematic Reviews (PROSPERO 2020: CRD42020182479) before its implementation. The protocol and the final report were developed based on the Cochrane Manual of Systematic Reviews of Interventions ${ }^{9}$.

\section{Review question}

What is the prevalence of comorbidities in all patients, patients admitted to the ICU, and in fatal cases affected by the new coronavirus (COVID-19)?

\section{Inclusion criteria}

This review considered studies that conducted epidemiological and clinical descriptions in patients and in fatal cases from different parts of the world, in order to determine the prevalence and geographic distribution of comorbidities in patients affected by COVID-19.

\section{Search strategy}

An initial search limited to MEDLINE was performed using MeSH index terms and related keywords. This search was followed by an analysis of the words in the text of the title, abstract, and index terms used to describe the articles. A second search using all the identified keywords and index terms was conducted on May 15, 2020 using the following databases: Latin American and Caribbean Health Sciences Literature (LILACS), the bibliographic database of the US National of Medicine (Medline), the Elsevier database (EMBASE), Web of Science and SCOPUS. The MeSH Index Term search included COVID-19, SARS-CoV2, prevalence, and comorbidity. As COVID-19 is a recent topic, thesis and dissertation papers have not yet been published and were not evaluated.

\section{Methodological quality assessment}

The articles selected for data recovery were analyzed by two independent reviewers who assessed the methodological validity of each text before their inclusion in this review. The quality of the publications included were evaluated based on the criteria derived from the Grading of Recommendations Assessment, Development and Evaluation method (GRADE). Points were awarded to the studies if they did not present limitations in study design or execution (risk of bias), inconsistency of results, evidence based on indirect data, imprecision, and publication bias. A score of four to five points was considered as high quality, three points as moderate quality, and zero to two points as low quality.

\section{Data extraction}

The data were added to the Review Manager (RevMan 5.3) for analysis. A data extraction table was created to assess the quality of demographic data, study location, sample size, number of cases, number of positives and the diagnostic test.

\section{Data synthesis}

The random-effect model meta-analysis method was used to analyze the pooled prevalence of comorbidities in patients and in fatal cases affected by COVID-19 in different parts of the world. The heterogeneity among the studies was analyzed using the Higgins test $\left(\mathrm{I}^{2}\right)$ that shows the percentage of variation among studies. These analyses were compiled by using the STATA software, version 12 (StataCorp LLC, Texas, USA). The Odds Ratio test, with a 95\% Confidence Interval (95\% CI), was calculated to measure the likelihood of death for a patient with a comorbidity compared to a patient without comorbidities.

\section{RESULTS}

Our search resulted in 1,150 manuscripts related to the search strategies used. The search strategy used for each database was: BVS (Comorbidades OR Comorbidities OR Comorbilidades) AND (("Infecções por Coronavirus" OR "Coronavirus Infections" OR "Infecciones por Coronavirus") OR (Betacoronavirus OR Betacoronavirus OR Betacoronavirus) OR (COVID-19) OR (SARS-CoV2)); PUBMED (Comorbidity OR Comorbidities) AND 
("Coronavirus Infections" OR Betacoronavirus OR COVID-19 OR SARS-CoV2); CINAHL (Comorbidity OR Comorbidities) AND ("Coronavirus Infections" OR Betacoronavirus OR COVID-19OR SARS-CoV2); EMBASE 2 ('comorbidity'/exp OR comorbidity OR 'comorbidities'/ exp OR comorbidities) AND ('coronavirus infection'/ exp OR 'coronavirus infection' OR 'betacoronavirus'/exp OR betacoronavirus OR' COVID 19'/exp OR ' COVID 19' OR 'sars cov2'); WEB OF SCIENCE (Comorbidit* AND ("Coronavirus Infections" OR Betacoronavirus OR COVID-19 OR SARS-CoV2); SCOPUS (Comorbidit* AND ("Coronavirus Infections" OR Betacoronavirus OR COVID-19 OR SARS-CoV2).

After applying the eligibility exclusion criteria (duplicate texts, articles related to other topics, text excluded by the review criteria or method quality), 42 studies were considered for analyses ${ }^{5-7,10-48}$. Of them, 39 were used to calculate the total prevalence of comorbidities in patients affected by COVID-19, six were used to calculate the prevalence of comorbidities in patients admitted to the ICU, and 11 were used to calculate the comorbidity prevalence in fatal cases. The characteristics of the studies included in this meta-analysis are shown in Table 1. The results of the search strategy are shown in a PRISMA flow chart (Figure 1). The data extracted from the final selection are shown in the Supplementary Table S1.

According to the criteria applied based on GRADE, the studies that met the selection criteria presented high methodological quality with a score of five. The $\mathrm{I}^{2}$ test indicated a low heterogeneity among the studies. Publication bias was not evaluated because the currently available methods are not considered useful for studies on proportions. The summaries of methodological quality and bias risk and applicability for each study and among the included studies are shown in the Supplementary Figures S1 and S2.

\section{Overall prevalence of comorbidities}

In the 39 studies used to calculate the pooled prevalence of comorbidities, 89,238 patients affected by COVID-19 were analyzed; $11,341(12.7 \%)$ presented one or more comorbidities, 2,172 (2.4\%) were admitted to the ICU, and $3,532(4 \%)$ patients died. The patients age range was 41 to 70 years. Among these studies, only one was conducted in the $\mathrm{USA}^{43}$, and included a large number of patients $(74,439)$ but did not segregate patients according to sex. In the other 38 studies, 14,844 patients were registered with a total of $8,518(57.4 \%)$ males and $6,413(42.6 \%)$ females. The reported comorbidities included hypertension, heart disease, diabetes, cancer, chronic obstructive pulmonary disease, asthma, chronic diseases of the liver, kidneys, digestive system, autoimmune disorders, immunodeficiencies, stroke, and others. Only one study specified which diseases were included in the category "Others".

Regarding the geographical distribution of the studied patients, 80,139 (88.7\%) were in the USA and 9,051

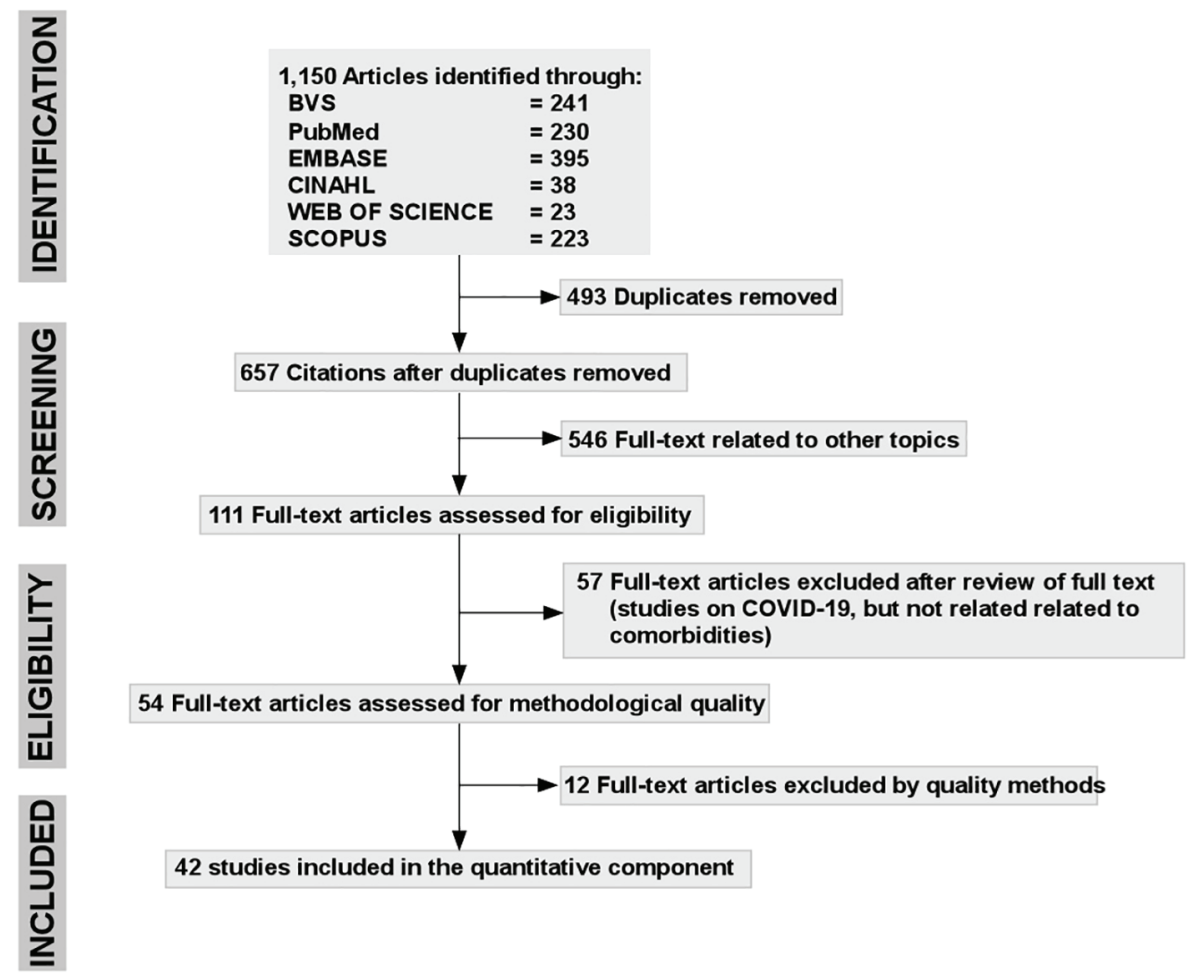

Figure 1 - A flowchart of the steps performed in the systematic review. 
Table 1 - A summary of the included studies.

\begin{tabular}{|c|c|c|c|c|c|c|c|c|c|c|c|}
\hline Study & Country & Total & ICU & Death & $\mathrm{M}$ & $F$ & Co $\%$ & $\mathrm{H} \%$ & CV \% & $D \%$ & COPD $\%$ \\
\hline Chen et al. ${ }^{5}$ & China & 99 & N.S. & 11 & 67 & 32 & 50.5 & 0.0 & +40 & 0.0 & 1.0 \\
\hline Wang et al. ${ }^{6}$ & China & 138 & 36 & 6 & 75 & 63 & 46.4 & 31.2 & 14.5 & 10.1 & 2.9 \\
\hline CDC Korea $^{7}$ & Korea & 54 & N.S. & 54 & 33 & 21 & 90.7 & 0.0 & 59.3 & 29.6 & 13.0 \\
\hline Cheng et al. ${ }^{10}$ & China & 698 & 138 & 113 & 367 & 331 & 42.6 & 33.4 & 0.0 & 14.3 & 1.9 \\
\hline Huang et al. ${ }^{11}$ & China & 41 & 13 & N.S. & 30 & 11 & 31.7 & 15.0 & 6.0 & 8.0 & 1.0 \\
\hline Liu et al. ${ }^{12}$ & China & 137 & 13 & 16 & 61 & 76 & 19.7 & 9.5 & 7.3 & 10.2 & 17.5 \\
\hline Liu et al. ${ }^{13}$ & China & 12 & 6 & N.S. & 7 & 5 & 58.3 & 25.0 & 33.3 & 16.6 & 8.3 \\
\hline Guan et al. ${ }^{14}$ & China & 1099 & 33 & 15 & 640 & 459 & 23.7 & 15.0 & 2.5 & 7.4 & 1.1 \\
\hline Du et al..$^{15}$ & China & 109 & 51 & 72 & 74 & 35 & 78.0 & 59.6 & +33.9 & 31.2 & 15.6 \\
\hline Guan et al. ${ }^{16}$ & China & 1590 & 99 & 50 & 904 & 686 & 25.0 & 20.3 & 3.8 & 9.0 & 1.5 \\
\hline Xu et al..$^{17}$ & China & 63 & 1 & 0 & 36 & 27 & 31.7 & 8.0 & 0.0 & 2.0 & 2.0 \\
\hline Chen et al. ${ }^{18}$ & China & 203 & N.S. & 26 & 108 & 95 & 43.3 & 12.9 & 3,4 & 2.7 & 3.9 \\
\hline Liang et al..$^{19}$ & China & 1590 & 90 & 50 & 904 & 674 & 25.1 & 16.9 & 3.7 & 8.2 & 1.5 \\
\hline Wang et al. ${ }^{20}$ & China & 399 & N.S. & 65 & 226 & 173 & 60.7 & 40.8 & 17.7 & 16.0 & 6.2 \\
\hline Cao et al. ${ }^{21}$ & China & 102 & N.S. & 17 & 53 & 49 & 46.1 & 27.5 & 4.9 & 10.8 & 9.8 \\
\hline Zhou et al. ${ }^{22}$ & China & 191 & 50 & 54 & 119 & 72 & 47.6 & 30.0 & 8.0 & 19.0 & 3.0 \\
\hline Zhang et al. ${ }^{23}$ & China & 120 & N.S. & 7 & 43 & 77 & 26.7 & 16.0 & 8.0 & 6.0 & 3.0 \\
\hline Chen et al. ${ }^{24}$ & China & 274 & N.S. & 113 & 171 & 103 & 48.5 & 34.0 & 8.0 & 17 & 7.0 \\
\hline Zhang et al..$^{25}$ & China & 140 & N.S. & N.S. & 71 & 69 & 64.3 & 30.0 & 5.0 & 12.1 & 1.4 \\
\hline Wang et al. ${ }^{26}$ & China & 69 & N.S. & 5 & 32 & 37 & 36.2 & 13.0 & 12.0 & 10.0 & 6.0 \\
\hline Yang et al. ${ }^{27}$ & China & 52 & 37 & 32 & 35 & 17 & 40.4 & 0.0 & 10.0 & 17.0 & 8.0 \\
\hline Wu et al. ${ }^{28}$ & China & 201 & 53 & 44 & 128 & 73 & 32.8 & 19.4 & 4.0 & 10.9 & 2.5 \\
\hline Huang et al. ${ }^{29}$ & China & 34 & 8 & N.S. & 20 & 14 & 47.1 & 23.5 & 17.6 & 11.8 & 2.9 \\
\hline Li et al. ${ }^{30}$ & China & 83 & 6 & N.S. & 44 & 39 & 18.1 & 6.0 & 1.2 & 7.8 & 6.0 \\
\hline Xu et al. ${ }^{31}$ & China & 90 & N.S. & N.S. & 39 & 51 & 50.0 & 19.0 & 3.0 & 6.0 & 1.0 \\
\hline Wu et al. ${ }^{32}$ & China & 80 & 0 & 0 & 39 & 41 & 47.5 & 0.0 & +31.2 & 6.2 & 1.2 \\
\hline Yang et al. ${ }^{33}$ & China & 149 & 0 & 0 & 81 & 68 & 34.9 & 0.0 & +18.7 & 6.0 & 0.7 \\
\hline Liu et al. ${ }^{34}$ & China & 3 & N.S. & N.S. & 2 & 1 & 33.3 & 0.0 & 0.0 & 33.3 & 33.3 \\
\hline Lei et al. ${ }^{35}$ & China & 34 & 15 & 7 & 14 & 20 & 58.8 & 58.8 & 20.6 & 23.5 & 2.9 \\
\hline Feng et al. ${ }^{36}$ & China & 476 & N.S. & 38 & 271 & 205 & 43.1 & 0.0 & 8.0 & 10.3 & 4.6 \\
\hline Yuan et al. ${ }^{37}$ & China & 27 & N.S. & 10 & 12 & 15 & 48.1 & 19.0 & 11.0 & 22.0 & 0.0 \\
\hline Mo et al. ${ }^{38}$ & China & 155 & N.S. & N.S. & 86 & 69 & 45.8 & 23.9 & 9.7 & 9.7 & 3.2 \\
\hline Wang et al. ${ }^{39}$ & China & 116 & 11 & 7 & 67 & 49 & 44.0 & 37.1 & 0.0 & 15.5 & 0 \\
\hline Zhang et al. ${ }^{40}$ & China & 221 & 23 & 12 & 108 & 113 & 35.3 & 24.4 & 10 & 10 & 2.7 \\
\hline Guo et al. ${ }^{41}$ & China & 256 & 45 & 43 & 91 & 165 & 73.0 & 32.6 & 11.2 & 15.0 & 2.1 \\
\hline Richardson et al..$^{42}$ & USA & 5700 & 373 & 553 & 3437 & 2263 & 93.9 & 56.6 & 11.1 & 33.8 & 5.4 \\
\hline Chow et al. ${ }^{43}$ & USA & 74439 & 1069 & 2112 & N.S. & N.S. & 3.6 & 0.0 & 9.0 & 10.9 & 9.2 \\
\hline Young et al. ${ }^{44}$ & Singapore & 18 & 2 & 0 & 9 & 9 & 27.8 & N.S. & N.S. & N.S. & N.S. \\
\hline Gupta et al. ${ }^{45}$ & India & 21 & N.S. & N.S. & 14 & 7 & 28.6 & 23.8 & 0.00 & 14.2 & 0.0 \\
\hline Grasselli et al. ${ }^{46}$ & Italy & 1591 & 1591 & N.S. & 1304 & 287 & 65.5 & 49.0 & 21.0 & 17.0 & 4.0 \\
\hline Du et al. ${ }^{47}$ & China & 85 & N.S. & 85 & 23 & 62 & 68.2 & 37.6 & 11.8 & 22.4 & 2.5 \\
\hline CDC Korea ${ }^{48}$ & Korea & 7755 & N.S. & 66 & 37 & 29 & 96.8 & 47.6 & 15.9 & 36.5 & 17.5 \\
\hline
\end{tabular}

ICU = Intensive Care Unit; M = Male; F = Female; Co. \% = Percentage of patients with comorbidities; $\mathrm{H} \%=$ Percentage of Chronic Heart Disease; CV \% = Percentage of Cardiovascular Disease; D \% = Percentage of Diabetes; COPD \% = Percentage of Chronic Obstructive Pulmonary Disease; CDC = Center for Disease Control and Prevention; + = Cardiovascular and Cerebrovascular Disease; N.S. = Not Specified 
$(10.1 \%)$ in China. This study also included 21 cases from India, 54 from South Korea, and 18 from Singapore, representing less than $1 \%$ of the total patients included.

The analysis of the general population affected by COVID-19 indicated a $42 \%$ pooled prevalence of comorbidities (95\% CI: 25-60; weight 100\%). In China, the geographical distribution analysis showed a $43 \%$ prevalence of comorbidities (95\% CI: 37-48; weight $89.4 \%$ ), followed by the USA with $8 \%$ (95\% CI: 7-8; weight 5.34\%), India $29 \%$ (95\% CI: 14-50; weight 2.59\%), and Singapore $28 \%$ (95\% CI: 12 -51; weight 2.58\%) (Figure 2).

Among those who had one or more previous diseases, there was a total of 16,222 comorbidities. Hypertension was the most prevalent in 32\% (95\% CI: 31-33; weight $6.54 \%$ ), followed by diabetes $22 \%$ (95\% CI: $21-23$; weight $6.57 \%$ ), heart disease $13 \%$ (95\% CI: 13-14; weight 6.62\%), and Chronic Obstructive Pulmonary Disease (COPD) 8\%
(95\% CI: 7-8; weight 6.65\%). In addition to these, other comorbidities were also assessed, such as kidney disease (5\%), cancer (3\%), asthma (3\%), liver disease (2\%), stroke (2\%), immunodeficiencies (2\%), and others $(8 \%)$. The pooled prevalence with $95 \% \mathrm{CI}$ values for each disease are shown in Table 2.

\section{Prevalence of comorbidities in ICU patients}

Of the six studies that conducted descriptions of the epidemiological and clinical profiles in patients admitted to the ICU, five divided the data according by sex. In these five studies, 1,661 patients were described ${ }^{6,11,13,36,48}$. Among these patients, $1,345(81 \%)$ were male, $316(19 \%)$ were female, and the age range was 46 to 63 years. The clinical characteristics of 2,730 patients were also described, indicating that $1,449(53 \%)$ had one or more comorbidities.

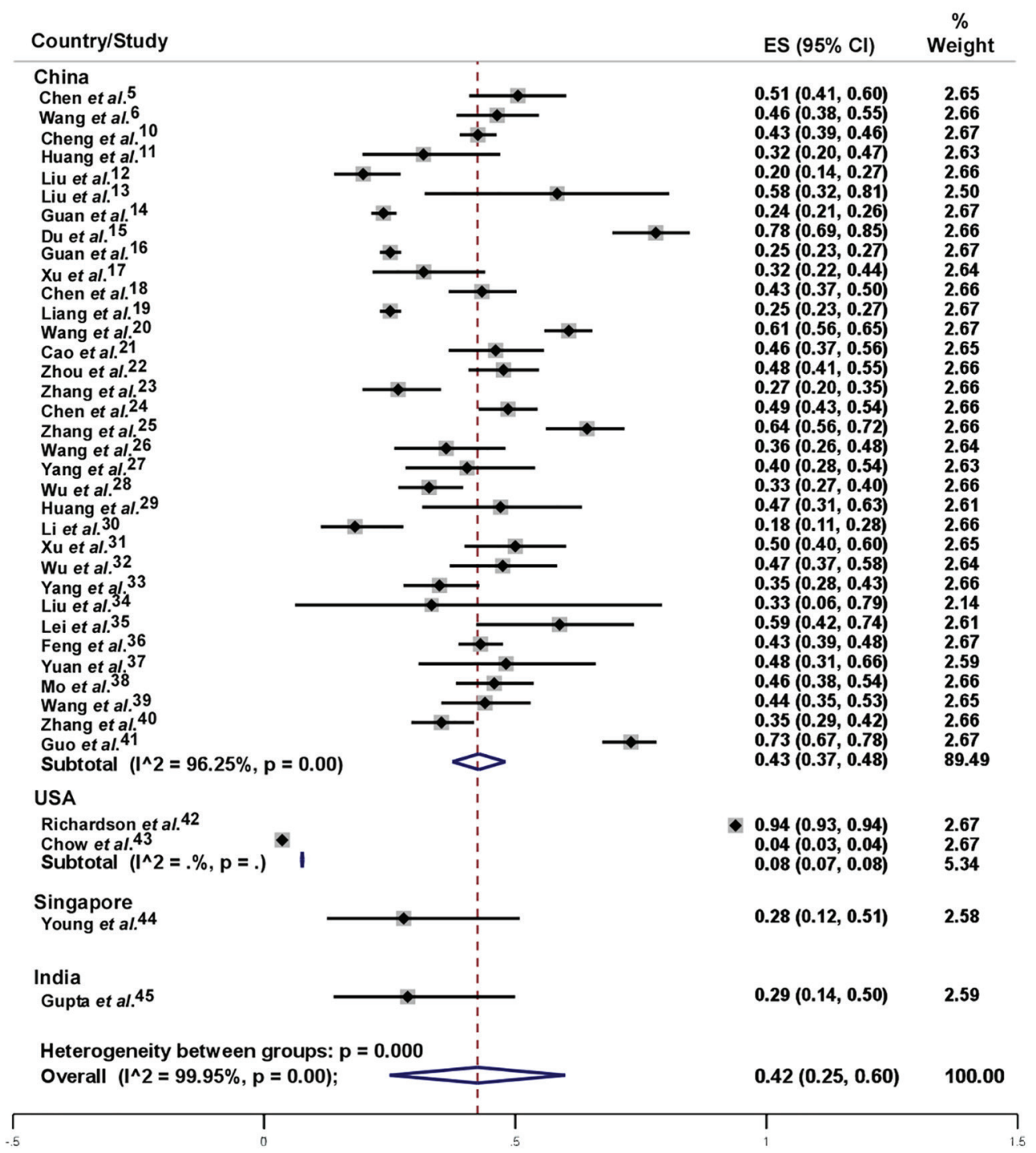

Figure 2 - Forest plot for a random-effect meta-analysis of comorbidities in all the patients affected by COVID-19. 
Table 2 - Overall prevalence of comorbidities, in the group admitted to the ICU and in the fatal cases by COVID-19.

\begin{tabular}{|c|c|c|c|c|c|c|c|c|c|}
\hline \multirow{2}{*}{ Comorbidity } & \multicolumn{3}{|c|}{ Overall Prevalence } & \multicolumn{3}{|c|}{ ICUs Patients } & \multicolumn{3}{|c|}{ Fatal Cases } \\
\hline & PP & $95 \% \mathrm{Cl}$ & $W \%$ & PP & $95 \% \mathrm{Cl}$ & $W \%$ & PP & $95 \% \mathrm{Cl}$ & $W \%$ \\
\hline Hypertension & 32 & $31-33$ & 6.54 & 27 & $25-29$ & 6.86 & 35 & $31-38$ & 8.10 \\
\hline Chronic Heart Disease & 13 & $13-14$ & 6.62 & 18 & $18-19$ & 7.15 & 17 & $14-20$ & 8.61 \\
\hline Diabetes & 22 & $21-23$ & 6.57 & 17 & $15-19$ & 7.17 & 19 & $16-22$ & 8.53 \\
\hline Malignancy & 3 & $3-4$ & 6.68 & 5 & $4-6$ & 7.81 & 5 & $4-7$ & 9.22 \\
\hline COPD & 8 & $7-8$ & 6.65 & 7 & $6-8$ & 7.67 & 9 & $7-11$ & 9.03 \\
\hline Asthma & 3 & $3-3$ & 6.69 & 0 & $0-0$ & 0.00 & 0 & $0-0$ & 0.00 \\
\hline Chronic Kidney Disease & 5 & $5-5$ & 6.67 & 5 & $6-8$ & 7.81 & 4 & $3-6$ & 9.29 \\
\hline Chronic Liver Disease & 2 & $1-2$ & 6.7 & 2 & $4-6$ & 8.01 & 3 & $2-4$ & 9.42 \\
\hline Cerebrovascular Accident & 2 & $1-3$ & 6.7 & 1 & $1-2$ & 8.05 & 6 & $5-9$ & 9.15 \\
\hline Immunodeficiency & 2 & $2-3$ & 6.69 & 2 & $1-3$ & 7.97 & 0 & $0-0$ & 0.00 \\
\hline Autoimmune Disease & 0 & $0-0$ & 6.71 & 0 & $0-0$ & 8.12 & 0 & $0-1$ & 9.57 \\
\hline $\begin{array}{l}\text { Cardiovascular and } \\
\text { Cerebrovascular Accident }\end{array}$ & 1 & $1-1$ & 6.71 & 0 & $0-0$ & 0.00 & 0 & $0-0$ & 0.00 \\
\hline Digestive Disease & 0 & $0-0$ & 6.71 & 0 & $0-1$ & 8.11 & 0 & $0-1$ & 9.60 \\
\hline Peripheral Vascular Disease & 0 & $1-0$ & 6.71 & 0 & $0-0$ & 8.12 & 0 & $0-0$ & 0.00 \\
\hline Other & 8 & $7-8$ & 6.65 & 18 & $16-19$ & 7.15 & 2 & $1-3$ & 9.48 \\
\hline Overall & 7 & $5-8$ & 100 & 7 & $6-8$ & 100 & 9 & $6-11$ & 100 \\
\hline
\end{tabular}

$\mathrm{ICU}=$ Intensive Care Unit; PP = Pooled Prevalence; $\mathrm{W}=$ Weight COPD = Chronic Obsctructive Pulmonary Disease; $\mathrm{Cl}=\mathrm{Confidence}$ Interval.

In total, there were 2,050 comorbidities among patients admitted to the ICU.

The pooled prevalence of comorbidities in ICU patients was $61 \%$ (95\% CI: $42-80$; weight $100 \%$ ). The geographical distribution analysis showed a $69 \%$ prevalence of comorbidities (95\% CI: 52-86; weight 61.09\%) in China, followed by Italy, with 66\% (95\% CI: 63-68; weight 19.47\%), and the USA, with 33\% (95\% CI: 31-36; weight $19.44 \%$ ). The forest plot for a random-effect meta-analysis of comorbidities in patients admitted to ICUs by COVID-19, are shown in the Supplementary Figure S3.

The most prevalent comorbidities in the ICU population were hypertension $26 \%$ (95\% CI: 25-29; weight 6.86\%), heart disease $18 \%$ (95\% CI: 16-19; weight $7.15 \%$ ), diabetes $17 \%$ (95\% CI: 16-19; weight 7.17\%), and others $17 \%$ (95\% CI: $16-19$; weight $7.15 \%$ ). In addition to these diseases, patients with COPD (7\%), cancer (5\%), kidney disease $(5 \%)$, liver disease (2\%), and stroke (1\%) were also evaluated. The pooled prevalence with the $95 \%$ CI values for each disease is shown in Table 2.

\section{Prevalence of comorbidities among mortality cases}

Eleven studies included descriptions of the epidemiological and clinical profiles of a total of 624 cases of mortality. In these studies, 394 patients were males and 218 females, with an age range between 64 and 70 years. Among the 624 fatal cases, 415 of the patients had one or more previous diseases, totaling 751 comorbidities. The pooled prevalence of comorbidities among the fatal cases was $77 \%$ (95\% CI: 68-86; weight 100\%). Only two countries were analyzed in the geographical distribution: China, with $71 \%$ (95\% CI: 63-82; weight 76.79\%) and Korea, with $92 \%$ (95\% CI: 87-97; weight 23.21\%) (Figure 3).

The most prevalent comorbidities in this population were hypertension 35\% (95\% CI: 25-29; weight 8.10\%), diabetes $19 \%$ (95\% CI: 16-22; weight $8.53 \%$ ), heart disease $17 \%$ (95\% CI: $14-20$; weight $8.61 \%$ ), and COPD $9 \%$ (95\% CI: 7-11; weight $9.22 \%$ ). In addition to these diseases, patients with cerebrovascular accident (6\%), cancer (5\%), kidney disease (4\%), liver disease (3\%), and other (2\%) were also evaluated. The pooled prevalence with $95 \% \mathrm{CI}$ values for each disease is shown in Table 2.

\section{Odds ratio}

The probability of a patient with comorbidity of dying from COVID-19, and the significance of this associations using the Fisher's exact test, were calculated. The number of patients with comorbidities who died and those who 


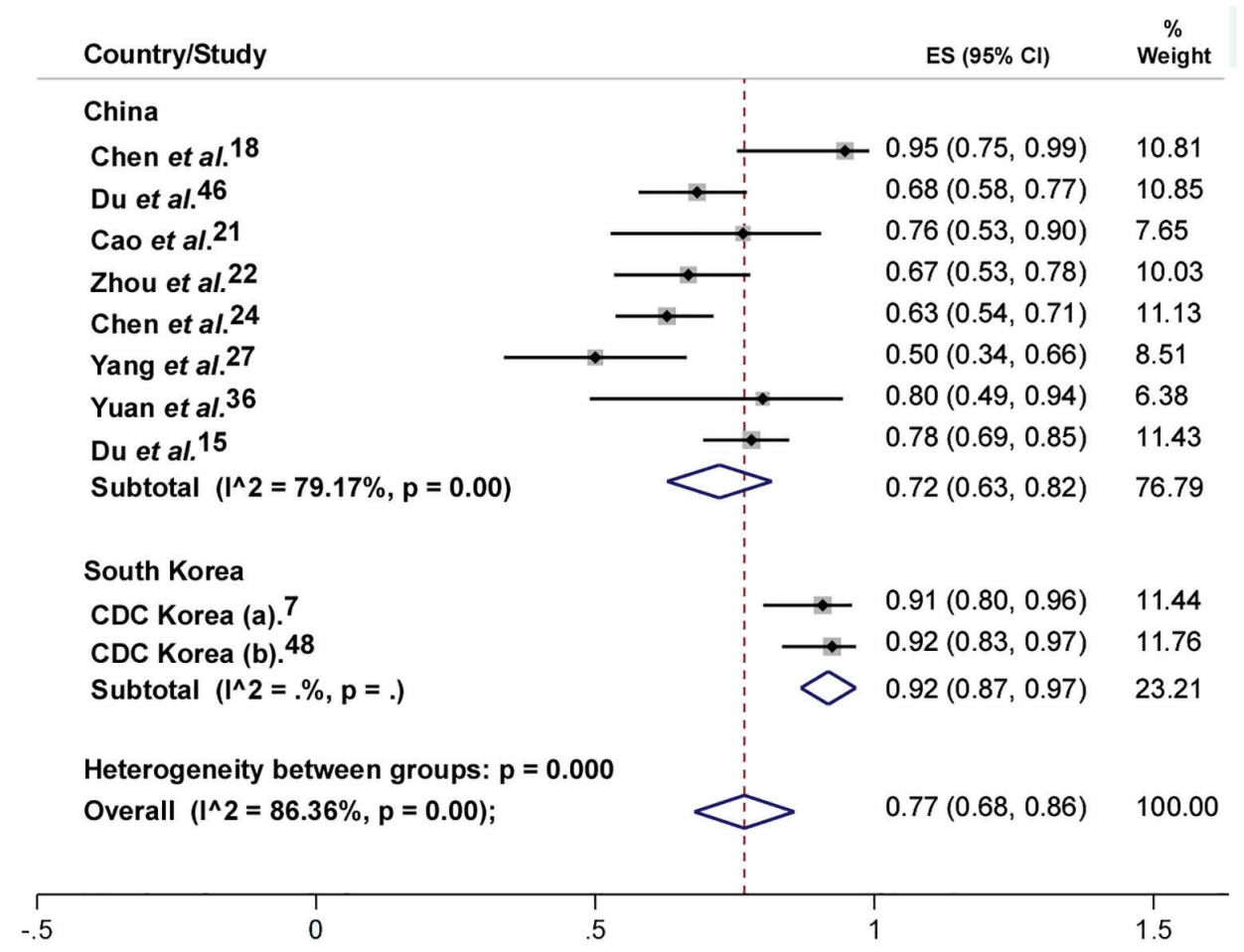

Figure 3 - Forest plot for a random-effect meta-analysis of comorbidities in fatal cases of COVID-19.

survived, in addition to the patients without comorbidities who died and who survived, were used to calculate an odds ratio of 2.4 with $95 \%$ CI $1.7-3.3$ and in the Fisher's exact test the value of $P<0.0001$.

\section{DISCUSSION}

This meta-analysis was based on 42 studies, including a large number of descriptions from China and the United States. Studies conducted in India, Italy, the United Kingdom, South Korea, and Singapore were also analyzed. A higher prevalence of male patients infected with COVID-19 was observed compared to females. This predisposition of the male sex was also observed in the diseases MERS-CoV and SARS-Co, which are also caused by viruses of the coronavirus family ${ }^{49,50}$.

The pooled prevalence of comorbidities in the general population of patients affected by the new coronavirus (COVID-19) was $42 \%$ (95\% CI: 26-59). China was the country with the highest prevalence, although there were also more studies analyzed from this country. However, it is important to highlight that two studies from the United States resulted in contrasting prevalence values (4\% and 94\%). Since the United States is the country that leads the statistics so far with the highest number of confirmed cases (more than one million) and deaths from coronavirus (more than seventy thousand), on May 8, 2020, it is of utmost importance to publish more data on the clinical characteristics of the disease in this country.

The results of this study confirm that the prevalence of comorbidities increases as the patient's clinical conditions worsens. In the general population affected by COVID-19, the prevalence of comorbidities was 42\%, 61\% among patients admitted to the ICU, and $77 \%$ among fatal cases. Males were the most affected in the three groups. On the other hand, the mean age also increases when we compare the group of patients in general with the group of fatal cases, as previously described among risk factors such as age, sex, and comorbidities ${ }^{4-7}$.

Regarding comorbidities, in the three groups analyzed (general population, admission to ICU, and fatal cases), hypertension was the most prevalent comorbidity, accounting for $32 \%, 26 \%$, and $35 \%$, respectively. In the general population, diabetes was the second-most prevalent (22\%) comorbidity, followed by heart disease (13\%) and COPD (8\%). However, in patients admitted to the ICU, diabetes $(17 \%)$ and heart disease $(18 \%)$ showed similar values. The same phenomenon was observed in fatal cases, with diabetes (19\%), and heart disease (17\%) showing similar values. Considering that type 1 diabetes mellitus usually manifests during childhood or adolescence, type 2 diabetes frequently manifests in adults, and heart diseases are more prevalent in older patients, one may think that the earlier onset of diabetes may account for it to rank second among the comorbidities in the general population affected 
by COVID-19. On the other hand, the group of fatal cases is composed of predominantly older adults, a population in which hypertension, diabetes, and heart disease are prevalent.

The odds ratio for any comorbidity was 2.4 with $95 \%$ CI 1.7-3.3 with a statistical significance of $P<0.0001$. In other words, a patient with a comorbidity has 2.4 times the chance of dying from COVID-19 compared to a patient without a comorbidity. This may explain the high prevalence of comorbidities among fatal cases,

In developing this study, we encountered several limitations. Firstly, not all studies segregated epidemiological and clinical data (age, sex, percentage of comorbidity, and patients hospitalized in the ICU). Secondly, some studies classified comorbidities in the "Other" category, but only one study described which diseases were comprised in this category. Thirdly, since China is the primary focus of the rise of the pandemic, most of the studies included were from this country. No studies from Africa, Oceania, or Latin America were found. Finally, in meta-analyses, it is recommended that publication bias are always assessed by statistical methods. However, currently available methods, such as the funnel plot and the Egger regression test, are not considered useful tools in studies on proportions ${ }^{51}$.

One can conclude that the existence of comorbidities increases the probability of dying from COVID-19 by 2.4 times compared to those who do not have pre-existing conditions. The most relevant comorbidities were shown to be hypertension, heart disease, and diabetes. Thus, comorbidities are more prevalent in the group of mortality cases when compared to the general population group. However, these conclusions are based on the evidence obtained, mostly from studies conducted in China. For this reason, studies describing the epidemiological and clinical profiles of COVID-19 cases in Africa, Oceania, and Latin America are recommended to clarify the behavior of this disease in these regions, and, thus, be able to apply effective measures aimed at safeguarding populations at risk.

\section{AUTHORS' CONTRIBUTIONS}

OAE and ASZ contributed to create and design the study, analyze, and interpret the data, and write the first and final version of the manuscript; EFA, FGL, TAM and PFB contributed to analyze data and wrote the first version of the manuscript. All authors approved the final version of the manuscript and are responsible for all aspects of the work, including ensuring its accuracy and integrity.

\section{REFERENCES}

1. World Health Organization. Coronavirus disease (COVID-19): situation report - 124. [cited 2020 Jun 13]. Available from: https://www.who.int/docs/default-source/coronaviruse/ situation-reports/20200523-covid-19-sitrep-124. pdf?sfvrsn=9626d639_2

2. Gorbalenya AE, Baker SC, Baric RS, de Groot RJ, Crosten C, Gulyaeva AA, et al. The species severe acute respiratory syndrome-related coronavirus: classifying 2019-nCoV and naming it SARS-CoV-2. Nat Microbiol. 2020;5:536-44.

3. Chan JF, Yuan S, Kok KH, To KK, Chu H, Yang J, et al. A familial cluster of pneumonia associated with the 2019 novel coronavirus indicatingperson-to-person transmission: a study of a family cluster. Lancet. 2020;395:514-23.

4. Cai H. Sex difference and smoking predisposition in patients with COVID-19. Lancet Respir Med. 2020;8:e20.

5. Chen N, Zhou M, Dong X, Qu J, Gong F, Han Y, et al. Epidemiological and clinical characteristics of 99 cases of 2019 novel coronavirus pneumonia in Wuhan, China: a descriptive study. Lancet. 2020;395:507-13.

6. Wang D, Hu B, Hu C, Zhu F, Liu X, Zhang J, et al. Clinical characteristics of 138 hospitalized patients with 2019 novel coronavirus-infected pneumonia in Wuhan, China. JAMA. 2020;323:1061-9.

7. Korean Society of Infectious Diseases, Korea Centers for Disease Control and Prevention. Analysis on 54 mortality cases of coronavirus disease 2019 in the Republic of Korea from January 19 to March 10, 2020. J Korean Med Sci. 2020;35:e132.

8. Yang J, Zheng Y, Gou X, Pu K, Chen Z, Guo Q, et al. Prevalence of comorbidities and its effects in coronavirus disease 2019 patients: a systematic review and meta-analysis. Int J Infect Dis. 2020;94:91-5.

9. Higgins JP, Green S, editors. Cochrane handbook for systematic reviews of interventions: version 5.1.0. London: The Cochrane Collaboration; 2011. [cited 2020 Jun 13]. Available from: http://handbook-5-1.cochrane.org/

10. Cheng Y, Luo R, Wang K, Zhang M, Wang Z, Dong L, et al. Kidney disease is associated with in-hospital death of patients with COVID-19. Kidney Int. 2020;97:829-38.

11. Huang C, Wang Y, Li X, Ren L, Zhao J, Hu Y, et al. Clinical features of patients infected with 2019 novel coronavirus in Wuhan, China. Lancet. 2020;395:497-506.

12. Liu K, Fang YY, Deng Y, Liu W, Wang MF, Ma JP, et al. Clinical characteristics of novel coronavirus cases in tertiary hospitals in Hubei Province. Chin Med J (Engl). 2020;133:1025-31.

13. Liu Y, Yang Y, Zhang C, Huang F, Wang F, Yuan J, et al. Clinical and biochemical indexes from 2019-nCoV infected patients linked to viral loads and lung injury. Sci China Life Sci. 2020;63:364-74. 
14. Guan WJ, Ni ZY, Hu Y, Liang WH, Ou CQ, He JX, et al. Clinical characteristics of coronavirus disease 2019 in China. N Engl J Med. 2020;382:1708-20.

15. Du RH, Liu LM, Yin W, Wang W, Guan LL, Yuan ML, et al. Hospitalization and critical care of 109 decedents with COVID-19 pneumonia in Wuhan, China. Ann Am Thorac Soc. 2020 In Press.

16. Guan WJ, Liang WH, Zhao Y, Liang HR, Chen ZS, Li WM, et al. Comorbidity and its impact on 1590 patients with Covid-19 in China: a nationwide analysis. Eur Respir J. 2020;55:2000547.

17. Xu XW, Wu XX, Jiang XG, Xu KJ, Ying LJ, Ma CL, et al. Clinical findings in a group of patients infected with the 2019 novel coronavirus (SARS-Cov-2) outside of Wuhan, China: retrospective case series. BMJ. 2020;368:m606.

18. Chen T, Dai Z, Mo P, Li X, Ma Z, Song S, et al. Clinical characteristics and outcomes of older patients with coronavirus disease 2019 (COVID-19) in Wuhan, China (2019): a singlecentered, retrospective study. J Gerontol A Biol Sci Med Sci. 2020:glaa089 In Press.

19. Liang WH, Guan WJ, Li CC, Li YM, Liang HR, Zhao Y, et al. Clinical characteristics and outcomes of hospitalised patients with COVID-19 treated in Hubei (epicenter) and outside Hubei (non-epicenter): a nationwide analysis of China. Eur Respir J. 2020;55:2000562.

20. Wang L, He W, Yu X, Hu D, Bao M, Liu H, et al. Coronavirus disease 2019 in elderly patients: characteristics and prognostic factors based on 4-week follow-up. J Infect. 2020;80:639-45.

21. Cao J, Tu WJ, Cheng W, Yu L, Liu YK, Hu X, et al. Clinical features and short-term outcomes of 102 patients with corona virus disease 2019 in Wuhan, China. Clin Infect Dis. 2020:ciaa243 In Press.

22. Zhou F, Yu T, Du R, Fan G, Liu Y, Liu Z, et al. Clinical course and risk factors for mortality of adult inpatients with COVID-19 in Wuhan, China: a retrospective cohort study. Lancet. 2020;395:1054-62.

23. Zhang R, Ouyang H, Fu L, Wang S, Han J, Huang K, et al. CT features of SARS-CoV-2 pneumonia according to clinical presentation: a retrospective analysis of 120 consecutive patients from Wuhan city. Eur Radiol. 2020 In Press.

24. Chen T, Wu D, Chen H, Yan W, Yan D, Chen G, et al. Clinical characteristics of 113 deceased patients with coronavirus disease 2019: retrospective study. BMJ. 2020;368:m1091.

25. Zhang JJ, Dong X, Cao YY, Yuan YD, Yang YB, Yan YQ, et al. Clinical characteristics of 140 patients infected with SARSCoV-2 in Wuhan, China. Allergy. 2020 In Press.

26. Wang Z, Yang B, Li Q, Wen L, Zhang R. Clinical features of 69 cases with coronavirus disease 2019 in Wuhan, China. Clin Infect Dis. 2020:ciaa272 In Press.

27. Yang X, Yu Y, Xu J, Shu H, Xia J, Liu H, et al. Clinical course and outcomes of critically ill patients with SARS-CoV-2 pneumonia in Wuhan, China: a single-centered, retrospective, observational study. Lancet Respir Med. 2020;8:475-81.

28. Wu C, Chen X, Cai Y, Xia J, Zhou X, Xu S, et al. Risk factors associated with acute respiratory distress syndrome and death in patients with coronavirus disease 2019 pneumonia in Wuhan, China. JAMA Intern Med. 2020 In Press.

29. Huang Y, Tu M, Wang S, Chen S, Zhou W, Chen D, et al. Clinical characteristics of laboratory confirmed positive cases of SARS$\mathrm{CoV}-2$ infection in Wuhan, China: a retrospective single center analysis. Travel Med Infect Dis. 2020:101606 In Press.

30. Li K, Wu J, Wu F, Guo D, Chen L, Fang Z, et al. The clinical and chest CT features associated with severe and critical COVID-19 pneumonia. Invest Radiol. 2020;55:327-31.

31. Xu X, Yu C, Qu J, Zhang L, Jiang S, Huang D, et al. Imaging and clinical features of patients with 2019 novel coronavirus SARS-CoV-2. Eur J Nucl Med Mol Imaging. 2020;47:1275-80.

32. Wu J, Liu J, Zhao X, Liu C, Wang W, Wang D, et al. Clinical characteristics of imported cases of COVID-19 in Jiangsu Province: a multicenter descriptive study. Clin Infect Dis. 2020:ciaa199 In Press.

33. Yang W, Cao Q, Qin L, Wang X, Cheng Z, Pan A, et al. Clinical characteristics and imaging manifestations of the 2019 novel coronavirus disease (COVID-19): a multi-center study in Wenzhou city, Zhejiang, China. J Infect. 2020;80:388-93.

34. Liu C, Wu C, Zheng X, Zeng F, Liu J, Wang P, et al. Clinical features and multidisciplinary treatment outcome of COVID-19 pneumonia: a report of three cases. J Formos Med Assoc. 2020 In Press.

35. Lei S, Jiang F, Su W, Chen C, Chen J, Mei W, et al. Clinical characteristics and outcomes of patients undergoing surgeries during the incubation period of COVID-19 infection. EClinicalMedicine. 2020;21:100331.

36. Feng Y, Ling Y, Bai T, Xie Y, Huang J, Li J, et al. COVID-19 with different severities: a multi-center study of clinical features. Am J Respir Crit Care Med. 2020;201:1380-8.

37. Yuan M, Yin W, Tao Z, Tan W, Hu Y. Association of radiologic findings with mortality of patients infected with 2019 novel coronavirus in Wuhan, China. PLoS One. 2020;15:e0230548.

38. Mo P, Xing Y, Xiao Y, Deng L, Zhao Q, Wang H, et al. Clinical characteristics of refractory COVID-19 pneumonia in Wuhan, China. Clin Infect Dis. 2020:ciaa270 In Press.

39. Wang L, Li X, Chen H, Yan S, Li D, Li Y, et al. Coronavirus disease 19 infection does not result in acute kidney injury: an analysis of 116 hospitalized patients from Wuhan, China. Am J Nephrol. 2020;51:343-8.

40. Zhang G, Hu C, Luo L, Fang F, Chen Y, Li J, et al. Clinical features and short-term outcomes of 221 patients with COVID-19 in Wuhan, China. J Clin Virol. 2020;127:104364.

41. Guo T, Fan Y, Chen M, Wu X, Zhang L, He T, et al. Cardiovascular implications of fatal outcomes of patients with coronavirus disease 2019 (COVID-19). JAMA Cardiol. 2020:e201017 In Press. 
42. Richardson S, Hirsch JS, Narasimhan M, Crawford JM, McGinn T, Davidson KW, et al. Presenting characteristics, comorbidities, and outcomes among 5700 patients hospitalized with COVID-19 in the New York City area. JAMA. 2020;323:20529.

43. Chow N, Fleming-Dutra K, Gierke R, Hall A, Hughes M, Pilishvili $\mathrm{T}$, et al. Preliminary estimates of the prevalence of selected underlying health conditions among patients with coronavirus disease 2019 - United States, February 12-March 28, 2020. MMWR Morb Mortal Wkly Rep. 2020;69:382-6.

44. Young BE, Ong SW, Kalimuddin S, Low JG, Tan SY, Loh J, et al. Epidemiologic features and clinical course of patients infected with SARS-CoV-2 in Singapore. JAMA. 2020;323:1488-94.

45. Gupta N, Agrawal S, Ish P, Mishra S, Gaind R, Usha G, et al. Clinical and epidemiologic profile of the initial COVID-19 patients at a tertiary care centre in India. Monaldi Arch Chest Dis. 2020;90:1294.

46. Grasselli G, Zangrillo A, Zanella A, Antonelli M, Cabrini L, Castelli A, et al. Baseline characteristics and outcomes of 1591 patients infected with SARS-CoV-2 admitted to ICUs of the Lombardy Region, Italy. JAMA. 2020;323:1574-81.
47. Du Y, Tu L, Zhu P, Mu M, Wang R, Yang P, et al. Clinical features of 85 fatal cases of COVID-19 from Wuhan: a retrospective observational study. Am J Respir Crit Care Med. 2020;201:1372-9.

48. COVID-19 National Emergency Response Center, Epidemiology and Case Management Team, Korea Centers for Disease Control and Prevention. Coronavirus disease-19: the first 7,755 cases in the Republic of Korea. Osong Public Health Res Perspect. 2020;11:85-90.

49. Badawi A, Ryoo SG. Prevalence of comorbidities in the Middle East respiratory syndrome coronavirus (MERS-CoV): a systematic review and meta-analysis. Int J Infect Dis. 2016;49:129-33.

50. Channappanavar R, Fett C, Mack M, Ten Eyck PP, Meyerholz DK, Perlman S. Sex-based differences in susceptibility to severe acute respiratory syndrome coronavirus infection. J Immunol. 2017;198:4046-53.

51. Murad MH, Chu H, Lin L, Wang Z. The effect of publication bias magnitude and direction on the certainty in evidence. BMJ Evid Based Med. 2018;23:84-6.

\section{SUPPLEMENTARY MATERIAL}

Table S1 - PRISMA Checklist.

\begin{tabular}{|c|c|c|c|}
\hline Section/topic & \# & Checklist item & Reported on page \# \\
\hline \multicolumn{4}{|l|}{ TITLE } \\
\hline Title & 1 & Identify the report as a systematic review, meta-analysis, or both. & Title \\
\hline \multicolumn{4}{|l|}{ ABSTRACT } \\
\hline Structured summary & 2 & $\begin{array}{l}\text { Provide a structured summary including, as applicable: background; } \\
\text { objectives; data sources; study eligibility criteria, participants, and } \\
\text { interventions; study appraisal and synthesis methods; results; limitations; } \\
\text { conclusions and implications of key findings; systematic review registration } \\
\text { number. }\end{array}$ & Abstract \\
\hline \multicolumn{4}{|l|}{ INTRODUCTION } \\
\hline Rationale & 3 & Describe the rationale for the review in the context of what is already known. & Introduction \\
\hline Objectives & 4 & $\begin{array}{l}\text { Provide an explicit statement of questions being addressed with reference } \\
\text { to participants, interventions, comparisons, outcomes, and study design } \\
\text { (PICOS). }\end{array}$ & $\begin{array}{l}\text { Introduction and } \\
\text { Methods: Review } \\
\text { Question. }\end{array}$ \\
\hline \multicolumn{4}{|l|}{ METHODS } \\
\hline $\begin{array}{l}\text { Protocol and } \\
\text { registration }\end{array}$ & 5 & $\begin{array}{l}\text { Indicate if a review protocol exists, if and where it can be accessed (e.g., } \\
\text { Web address), and, if available, provide registration information including } \\
\text { registration number. }\end{array}$ & Methods \\
\hline Eligibility criteria & 6 & $\begin{array}{l}\text { Specify study characteristics (e.g., PICOS, length of follow-up) and report } \\
\text { characteristics (e.g., years considered, language, publication status) used } \\
\text { as criteria for eligibility, giving rationale. }\end{array}$ & $\begin{array}{c}\text { Methods: Inclusion } \\
\text { Criteria }\end{array}$ \\
\hline Information sources & 7 & $\begin{array}{l}\text { Describe all information sources (e.g., databases with dates of coverage, } \\
\text { contact with study authors to identify additional studies) in the search and } \\
\text { date last searched. }\end{array}$ & $\begin{array}{c}\text { Methods: Search } \\
\text { Strategy }\end{array}$ \\
\hline
\end{tabular}


Table S1 - PRISMA Checklist (cont.).

\begin{tabular}{|c|c|c|c|}
\hline Section/topic & \# & Checklist item & Reported on page \# \\
\hline Search & 8 & $\begin{array}{l}\text { Present full electronic search strategy for at least one database, including } \\
\text { any limits used, such that it could be repeated. }\end{array}$ & $\begin{array}{l}\text { Methods: Search } \\
\text { Strategy }\end{array}$ \\
\hline Study selection & 9 & $\begin{array}{l}\text { State the process for selecting studies (i.e., screening, eligibility, included in } \\
\text { systematic review, and, if applicable, included in the meta-analysis). }\end{array}$ & $\begin{array}{l}\text { Methods: Study } \\
\text { Strategy }\end{array}$ \\
\hline $\begin{array}{l}\text { Data collection } \\
\text { process }\end{array}$ & 10 & $\begin{array}{l}\text { Describe method of data extraction from reports (e.g., piloted forms, } \\
\text { independently, in duplicate) and any processes for obtaining and confirming } \\
\text { data from investigators. }\end{array}$ & $\begin{array}{l}\text { Methods: Data } \\
\text { extraction }\end{array}$ \\
\hline Data items & 11 & $\begin{array}{l}\text { List and define all variables for which data were sought (e.g., PICOS, funding } \\
\text { sources) and any assumptions and simplifications made. }\end{array}$ & $\begin{array}{l}\text { Methods: Data } \\
\text { extraction/Quality } \\
\text { assessment }\end{array}$ \\
\hline $\begin{array}{l}\text { Risk of bias in } \\
\text { individual studies }\end{array}$ & 12 & $\begin{array}{l}\text { Describe methods used for assessing risk of bias of individual studies } \\
\text { (including specification of whether this was done at the study or outcome } \\
\text { level), and how this information is to be used in any data synthesis. }\end{array}$ & $\begin{array}{l}\text { Additional File. } \\
\text { Figure S1. }\end{array}$ \\
\hline Summary measures & 13 & State the principal summary measures (e.g., risk ratio, difference in means). & $\begin{array}{l}\text { Methods: Data } \\
\text { Synthesis }\end{array}$ \\
\hline Synthesis of results & 14 & $\begin{array}{l}\text { Describe the methods of handling data and combining results of studies, if } \\
\text { done, including measures of consistency }\left(e . g ., I^{2}\right) \text { for each meta-analysis. }\end{array}$ & $\begin{array}{l}\text { Methods: Data } \\
\text { Synthesis }\end{array}$ \\
\hline $\begin{array}{l}\text { Risk of bias across } \\
\text { studies }\end{array}$ & 15 & $\begin{array}{l}\text { Specify any assessment of risk of bias that may affect the cumulative } \\
\text { evidence (e.g., publication bias, selective reporting within studies). }\end{array}$ & $\begin{array}{l}\text { Additional File. } \\
\text { Figure S2. }\end{array}$ \\
\hline Additional analyses & 16 & $\begin{array}{l}\text { Describe methods of additional analyses (e.g., sensitivity or subgroup } \\
\text { analyses, meta-regression), if done, indicating which were pre-specified. }\end{array}$ & $\begin{array}{l}\text { Methods: Data } \\
\text { Synthesis }\end{array}$ \\
\hline \multicolumn{4}{|l|}{ RESULTS } \\
\hline Study selection & 17 & $\begin{array}{l}\text { Give numbers of studies screened, assessed for eligibility, and included in the } \\
\text { review, with reasons for exclusions at each stage, ideally with a flow diagram. }\end{array}$ & $\begin{array}{l}\text { Results } \\
\text { (Figure 1) }\end{array}$ \\
\hline Study characteristics & 18 & $\begin{array}{l}\text { For each study, present characteristics for which data were extracted (e.g., } \\
\text { study size, PICOS, follow-up period) and provide the citations. }\end{array}$ & $\begin{array}{l}\text { Results } \\
\text { (Table 1) }\end{array}$ \\
\hline $\begin{array}{l}\text { Risk of bias within } \\
\text { studies }\end{array}$ & 19 & $\begin{array}{l}\text { Present data on risk of bias of each study and, if available, any outcome } \\
\text { level assessment (see item 12). }\end{array}$ & $\begin{array}{l}\text { Additional File. } \\
\text { Figure S2 and } \\
\text { Figure S1. }\end{array}$ \\
\hline $\begin{array}{l}\text { Results of individual } \\
\text { studies }\end{array}$ & 20 & $\begin{array}{l}\text { For all outcomes considered (benefits or harms), present, for each study: } \\
\text { (a) simple summary data for each intervention group (b) effect estimates } \\
\text { and confidence intervals, ideally with a forest plot. }\end{array}$ & $\begin{array}{l}\text { Results. } \\
\text { Figure 2, } 3 \text { and } 4 .\end{array}$ \\
\hline Synthesis of results & 21 & $\begin{array}{l}\text { Present results of each meta-analysis done, including confidence intervals } \\
\text { and measures of consistency. }\end{array}$ & $\begin{array}{c}\text { Results } \\
\text { (Figures 2, } 3 \text { and 4) }\end{array}$ \\
\hline $\begin{array}{l}\text { Risk of bias across } \\
\text { studies }\end{array}$ & 22 & $\begin{array}{l}\text { Present results of any assessment of risk of bias across studies (see Item } \\
\text { 15). }\end{array}$ & $\begin{array}{l}\text { Additional File. } \\
\text { Figure S2. }\end{array}$ \\
\hline Additional analysis & 23 & $\begin{array}{l}\text { Give results of additional analyses, if done (e.g., sensitivity or subgroup } \\
\text { analyses, meta-regression [see Item 16]). }\end{array}$ & Results (Odds Ratio) \\
\hline \multicolumn{4}{|l|}{ DISCUSSION } \\
\hline $\begin{array}{l}\text { Summary of } \\
\text { evidence }\end{array}$ & 24 & $\begin{array}{l}\text { Summarize the main findings including the strength of evidence for each } \\
\text { main outcome; consider their relevance to key groups (e.g., healthcare } \\
\text { providers, users, and policy makers). }\end{array}$ & Discussion \\
\hline Limitations & 25 & $\begin{array}{l}\text { Discuss limitations at study and outcome level (e.g., risk of bias), and at } \\
\text { review-level (e.g., incomplete retrieval of identified research, reporting bias). }\end{array}$ & Discussion \\
\hline Conclusions & 26 & $\begin{array}{l}\text { Provide a general interpretation of the results in the context of other } \\
\text { evidence, and implications for future research. }\end{array}$ & Conclusion \\
\hline \multicolumn{4}{|l|}{ FUNDING } \\
\hline Funding & 27 & $\begin{array}{l}\text { Describe sources of funding for the systematic review and other support } \\
\text { (e.g., supply of data); role of funders for the systematic review. }\end{array}$ & NA \\
\hline
\end{tabular}




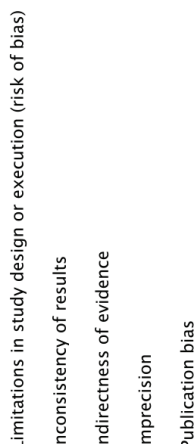

\begin{tabular}{|c|c|c|c|c|c|}
\hline Cao et al. ${ }^{21}$ & $\oplus$ & $\oplus$ & $\uparrow$ & 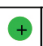 & 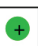 \\
\hline CDC Korea $(a)^{7}$ & 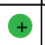 & ๑ & 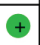 & + & + \\
\hline CDC Korea $(b)^{48}$ & $\oplus$ & 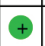 & + & $\oplus$ & 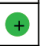 \\
\hline Chen et al. ${ }^{5}$ & + & + & $\hookrightarrow$ & $\hookrightarrow$ & + \\
\hline Chen et al. ${ }^{18}$ & + & 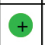 & 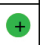 & 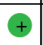 & + \\
\hline Chen et al. ${ }^{24}$ & + & 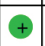 & († & + & + \\
\hline Cheng et al. ${ }^{10}$ & + & + & $\hookrightarrow$ & + & + \\
\hline Chow et al. ${ }^{43}$ & + & + & $\hookrightarrow$ & + & + \\
\hline Du et al. ${ }^{15}$ & + & + & † & $\hookrightarrow$ & + \\
\hline Du et al. ${ }^{47}$ & + & + & † & $\uparrow$ & + \\
\hline Feng et al. ${ }^{36}$ & 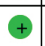 & + & $\hookrightarrow$ & $\hookrightarrow$ & + \\
\hline Grasselli et al. ${ }^{46}$ & $\oplus$ & 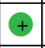 & + & + & $\oplus$ \\
\hline Guan et al. ${ }^{14}$ & $\oplus$ & + & + & 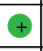 & 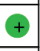 \\
\hline Guan et al. ${ }^{16}$ & + & + & + & + & + \\
\hline Guo et al. ${ }^{41}$ & + & 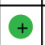 & 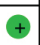 & + & + \\
\hline Gupta et al. ${ }^{45}$ & + & + & $\hookrightarrow$ & + & + \\
\hline Huang et al. ${ }^{11}$ & + & + & + & + & + \\
\hline Huang et al. ${ }^{29}$ & + & + & + & 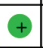 & + \\
\hline Lei et al. ${ }^{35}$ & + & († & † & + & + \\
\hline Liang et al..$^{19}$ & $\oplus$ & + & + & + & + \\
\hline Li et al. ${ }^{30}$ & + & ๑ & $\hookrightarrow$ & 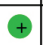 & + \\
\hline Liu et al. ${ }^{12}$ & 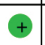 & + & + & + & + \\
\hline Liu et al. ${ }^{13}$ & + & + & 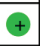 & + & 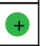 \\
\hline Liu et al. ${ }^{34}$ & + & + & + & + & 4 \\
\hline Mo et al. ${ }^{38}$ & 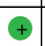 & 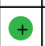 & + & 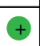 & + \\
\hline ichardson et al. ${ }^{42}$ & 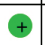 & + & († & + & + \\
\hline Wang et al. ${ }^{6}$ & $\odot$ & + & 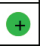 & + & + \\
\hline Wang et al. ${ }^{20}$ & 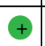 & 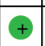 & 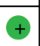 & + & + \\
\hline Wang et al. ${ }^{26}$ & $\oplus$ & $\oplus$ & + & + & + \\
\hline Wang et al. ${ }^{39}$ & 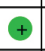 & + & + & + & + \\
\hline Wu et al. ${ }^{28}$ & + & + & † & + & + \\
\hline Wu et al. ${ }^{32}$ & (†) & (†) & 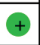 & + & + \\
\hline Xu et al. ${ }^{17}$ & + & + & + & + & + \\
\hline Xu et al. ${ }^{31}$ & $\oplus$ & $\oplus$ & 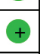 & + & + \\
\hline Yang et al. ${ }^{27}$ & $\oplus$ & 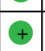 & † & + & + \\
\hline Yang et al. ${ }^{33}$ & + & + & + & + & + \\
\hline Young et al..$^{44}$ & + & 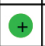 & 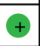 & + & + \\
\hline Yuan et al. ${ }^{37}$ & + & + & + & 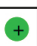 & + \\
\hline Zhang et al. ${ }^{23}$ & $\oplus$ & + & + & + & + \\
\hline Zhang et al. ${ }^{25}$ & + & + & 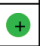 & + & + \\
\hline Zhang et al. ${ }^{40}$ & $\oplus$ & 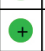 & + & + & + \\
\hline Zhou et al. ${ }^{22}$ & + & († & + & + & + \\
\hline
\end{tabular}

Figure S1 - The methodological quality summary bias risk concern and applicability for each study. 


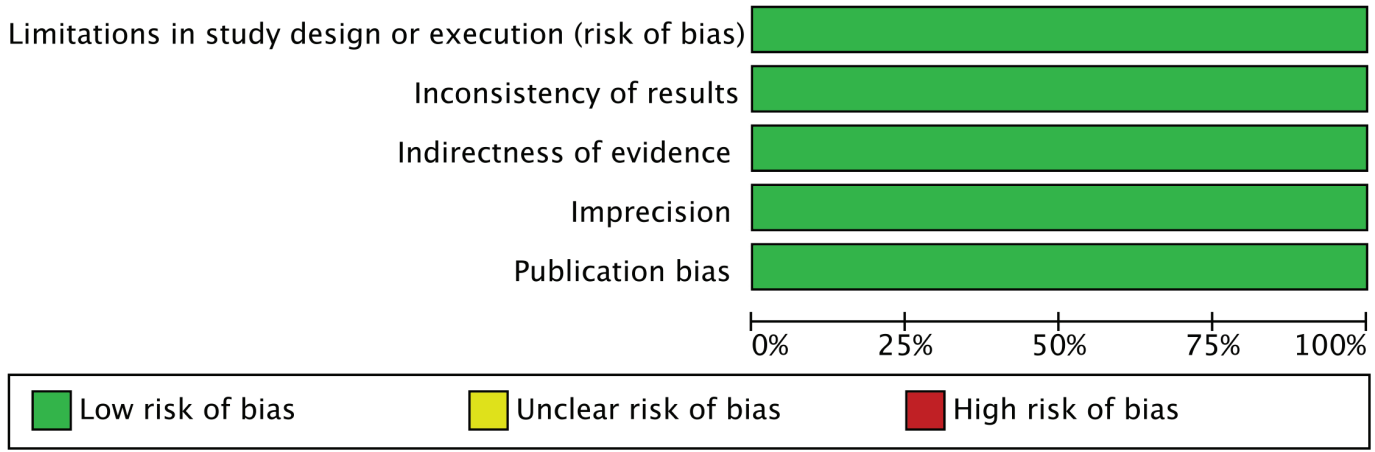

Figure S2 - The methodological quality summary bias risk concern and applicability for across the included studies.

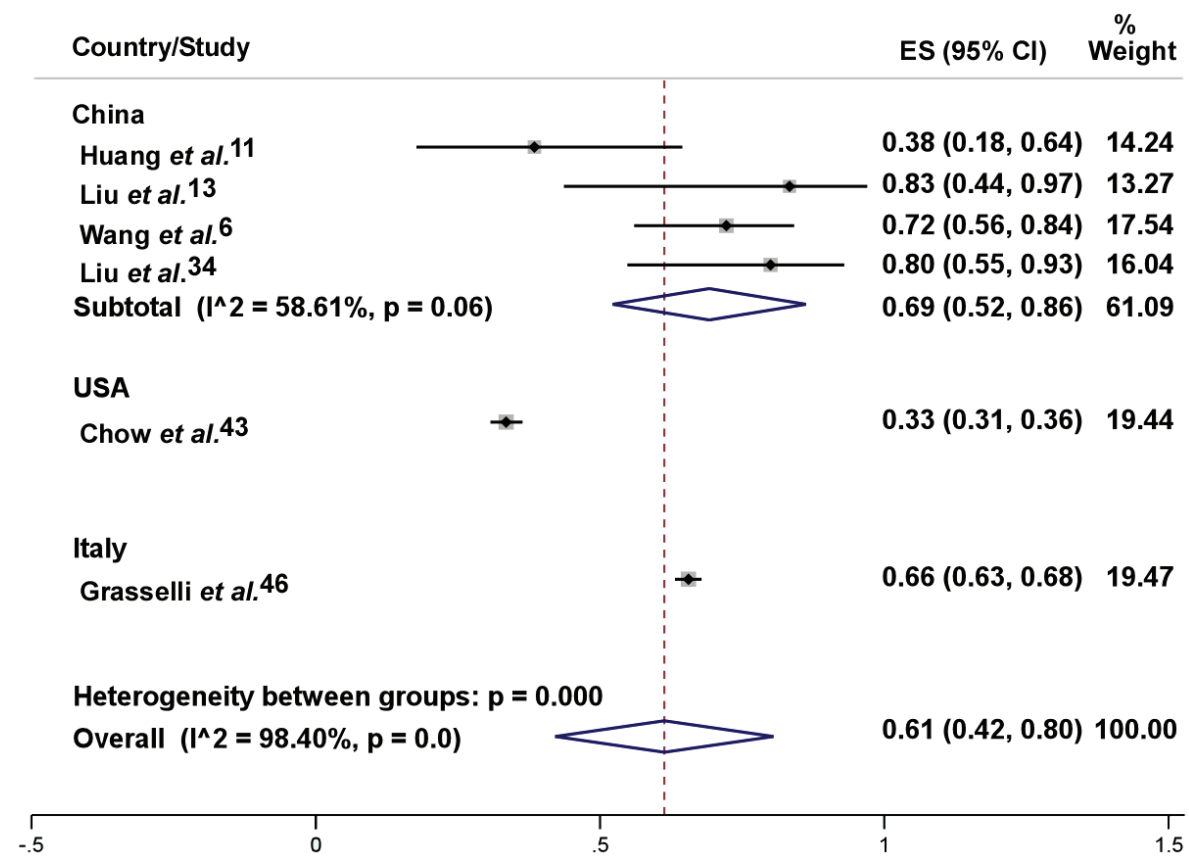

Figure S3 - The forest plot for a random-effect meta-analysis of comorbidities in patients admited in ICUs. 